This item was submitted to Loughborough's Research Repository by the author.

Items in Figshare are protected by copyright, with all rights reserved, unless otherwise indicated.

\title{
Parentification: counselling talk on a helpline for children and young people
}

PLEASE CITE THE PUBLISHED VERSION

https://www.palgrave.com/gp/book/9781137428301

\section{PUBLISHER}

(C) Palgrave Macmillan

\section{VERSION}

AM (Accepted Manuscript)

\section{PUBLISHER STATEMENT}

This work is made available according to the conditions of the Creative Commons Attribution-NonCommercialNoDerivatives 4.0 International (CC BY-NC-ND 4.0) licence. Full details of this licence are available at: https://creativecommons.org/licenses/by-nc-nd/4.0/

\section{LICENCE}

CC BY-NC-ND 4.0

\section{REPOSITORY RECORD}

Danby, Susan, Jakob Cromdal, Johanna Rendle-Short, Carly W. Butler, Karin Osvaldsson, and Michael Emmison. 2019. "Parentification: Counselling Talk on a Helpline for Children and Young People". figshare. https://hdl.handle.net/2134/17940. 


\title{
To appear in Palgrave Handbook of Child Mental Health (2015)
}

\section{CHAPTER xxx: PARENTIFICATION: COUNSELLING TALK ON A HELPLINE FOR CHILDREN AND YOUNG PEOPLE}

Susan Danby (Queensland University of Technology), Jakob Cromdal (Linkoping University), Johanna Rendle-Short (Australian National University), Carly W. Butler (Loughborough University), Karin Osvaldsson (Linkoping University), Michael Emmison (University of Queensland).

\section{Chapter contents}

1. Introduction

2. Project Overview

3. Analysis

4. Discussion

5. Clinical Relevance

6. Summary

7. Clinical Practice

8. Recommended Reading

9. References

\begin{abstract}
:
This chapter investigates counselling interactions where young clients talk about their experiences of taking on family responsibilities normatively associated with parental roles. In research counselling literature, practices where relationships in families operate so that there is a reversal of roles, with children managing the households and caring for parents and siblings, is described as parentification. Parentification is used in the counselling literature as a clinician/researcher term, which we 'respecify' (Garfinkel, 1991) the term by beginning with an investigation of young clients' own accounts of being an adult or parent and how counsellors orient to these accounts. As well as providing understandings of how young people propose accounts of their experiences of adult-child role reversal, the chapter contributes to understanding how children and young people use the resources of counselling helplines, and how counsellors can communicate effectively with children and young people.
\end{abstract}




\section{Introduction: The concept of parentification}

This chapter investigates young clients' accounts of their experiences of caring for family members, roles normatively associated with being an adult or parent, and how counsellors orient to their accounts. The counselling sessions occurred in phone and web chat sessions on Kids Helpline, an Australian national helpline for children and young people.

The concept of parentification refers to the reversal of roles within family relationships, with children managing the household and caring for parents and siblings (Jankowski, Hooper, Sandage, \& Hannah, 2013; McMahon \& Luthar, 2007). These practices can be found in contexts of dysfunctional family dynamics, or in response to a family crisis, such as a parent with a serious illness (McMahon \& Luthar, 2007). Parentification can involve two kinds of children's support for parents, instrumental and emotional, and sometimes both come into play when caring for parents and younger siblings, looking after the household and generally acting as an adult (Leon \& Rudy, 2005; McMahon \& Luthar, 2007). Parentification is often described as the blurring of parent-child roles, breaking down the "generational hierarchy," with the consequence of children and young people coping with stress and anxiety (Hooper, 2008). The concept of parentification is not to be confused with children helping to some extent with household chores or other family responsibilities, such as caring for younger children, activities that are considered to develop concepts of altruism and positive self-identity (McMahon \& Luthar, 2007).

Many studies of parentification have relied on retrospective reports by adults about their childhood, although more recently children are being directly asked about their experiences (Earley \& Cushway, 2002). In a study that reported on how adolescent daughters managed when the mother had been diagnosed with breast cancer, the daughters reported that they had difficulties attending to the needs of their mother as well as their own needs (Stiffler, Barada, Hosei, \& Haase, 2008). 
They struggled to isolate themselves from the new responsibilities by escaping from the situation, but also not wanting to leave their mothers without support, recognizing that their mothers required increased care and someone else to be responsible for everyday household tasks (Stiffler et al., 2008). In study of parental conflict, Leon and Rudy (2005) found that young children of parents who had higher levels of parental conflict drew pictures of themselves more often taking on an adult caring role in the family. A Belgian study of children aged 7-14 years focused on the children's experiences of caring for parents with depression. The children reported not feeling recognized for the care they gave, and also reported protecting their parents by not disclosing their emotional states or discussing sensitive or difficult topics (Van Parys \& Rober, 2013).

Parentification can affect children's mental health outcomes. In their study of almost 800 university students in the USA, Jankowski and colleagues (2013) examined the negative effects of parentification. The students in their study described a sense of unfairness and injustice due to their own needs being unmet, including negative emotions such as stress. Parentification has been found to have a negative effect on children's long-term wellbeing well into adulthood, where they experience 'imposter' feelings of being an adult: feeling "like a child trying to behave like an adult" (Castro, Jones, \& Mirsalimi, 2004, p. 209). More recent studies show how parentification can lead to some positive short and longer term benefits for children, such as an increased sense of competence, particularly when children reported that the responsibilities they undertook were recognized by the parents (Hooper, 2008; Jankowski et al., 2013).

While parentification is a well-known concept in clinical research, to date there are relatively few empirical studies to specifically explore the phenomenon (Leon \& Rudy, 2005; McMahon \& Luthar, 2007). There is even less written about therapeutic support and intervention (see however, DiCaccavo, 2006). By investigating how young clients talk about their experiences of acting like an adult, undertaking roles such as caring for family members, including parents and siblings, we show the 
'when' and 'how' experiences of parentification introduced by young people and discussed within a therapeutic context of a helpline dealing specifically with young clients. Considering the strategies that young people use to talk about their experiences has application for understanding the concerns that they might face and ways to support them in these situations.

\section{Project Overview}

The data reported here consists of a subset from 50 audio-recorded telephone calls and 100 logged synchronous web chat counselling interactions on Kids Helpline (Danby, Butler, \& Emmison, 2009; Harris, Danby, Butler, \& Emmison, 2012). Older clients are more likely to use web chat and email, whereas younger clients are more likely to use the phone (BoysTown, 2013). As well, more serious issues such as self harm and suicidal thoughts are more likely to be discussed within an online environment (BoysTown, 2013). Approval was sought and given to use the transcripts of the audio-recorded phone calls and chat/email logs. Names and other identifying information were replaced with pseudonyms.

In 2013, almost 250,000 young people aged 5-25 years made contact with Kids Helpline, with mental health concerns the main reason for contact (BoysTown, 2013). The counsellors are paid professionals, and have university qualifications in counselling, psychology or social work. In line with the helpline philosophy "We care, we listen", counsellors encourage and support the children and young people (Danby, Baker, \& Emmison, 2005; Emmison \& Danby, 2007).

Counsellors on Kids Helpline support young clients to tell their troubles and they respond with counselling support. They provide interactional space for children and young people to design their own way into the counselling sessions, and respond with displays of sensitivity that draw on the skill of the counsellors to actively listen across a mode of modalities, including counselling through telephone calls, web chat and email modalities (Danby, Baker, \& Emmison, 2005; Danby, Butler \& Emmison, 2009). The counsellors use strategies such as questions designed to help clients 
consider their own situations and to come up with solutions, to empower clients through promoting self-directedness, an essential component of the Kids Helpline philosophy (Butler, Potter, Danby, Emmison, \& Hepburn, 2010). Another strategy that counsellors use is where they volunteer detailed models, described as script proposals, of what clients could say to a third party, such as friend or a parent (Emmison, Butler, \& Danby, 2011).

In this chapter, we use ethnomethodological and conversation analysis approaches to 'respecify' (Garfinkel, 1991) the term parentification by beginning with how the young people and counsellors "produce and exhibit ...logically, reflexively accountable orderliness" (p. 17) as they talk about experiences of caring for their family members in ways that clinicians or researchers might identify as parentification. One focus of our analysis is the use of category work by client and counsellor; that is, how each orient to the clients' family relationships drawing on commonsense and normative categorizations that orient to distributions of family rights and responsibilities, and normative life spans. Through analysis, we show how membership categorization is "an activity that is carried out in particular local circumstances" (Hester \& Eglin, 1997, p. 22). It is in the "use of these categories that culture is constituted" (Hester \& Eglin, 1997, p. 20). Here, family and stage-of-life devices are made relevant by young clients and counsellors to make sense of family relationships and to validate clients' accounts of their experiences.

\section{Analysis}

Below, we present extracts from two counselling sessions of children and young people presenting accounts of their experiences of caring for family members. Extract 1 is of a young caller using phone counselling, and Extract 2 is from a web counselling session. (See Endnote 1 at the end of this chapter for an explanation of how to understand the time stamps on the transcript.) These two extracts show the phenomenon under discussion.

Extract 1 (PC150508_1807) (phone) 


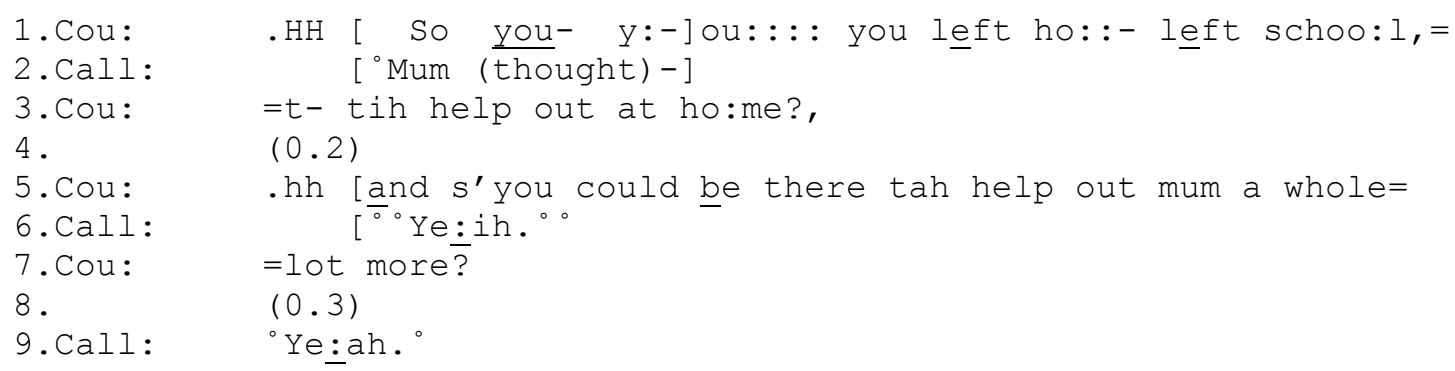

Extract 2 (WC103531) (web chat)

(Counsellor) how do you feel about your mum being like that?

16:22 18:39 00:55 um it kinda sucks. i would like her to look after me for once. and

(Client) nurse me when im not well or hug me when i cry etc. but i have 16:23 19:20 00:41 come to accept thats not gonna happen so $\mathrm{i}$ just have to lump it.

(Counsellor) it's good that you look after you mum like that and take such a
big responsibility. Do you ever put your own needs first? she is mainly my first priority. she is so needy and when i was (Client) younger $\mathrm{i}$ couldnt help and just had to watch and now i can $\mathrm{i}$ feel 16:25 21:43 00:46 and obligation to protect her.

In Extracts 1 and 2, counsellors and clients did not directly refer to parentification practices, although they did talk about young people undertaking caring roles in looking after parents. As researchers, we rely on clients' own accounts of their experiences and emotions, and how the counsellors respond to these descriptions, but we do not name them as instances of parentification.

In the two cases we discuss below, beginning with Extract 3, we show how members describe situations, problems, and experiences as a way of producing and recognizing particular activities that go along with the category of being a young person (Atkinson, 1980), and the difficulties they report acting within a social category usually associated with adults and parents. The membership categorization devices of family and stage-of-life (SOL) are used by counsellors and clients alike in counselling on Kids Helpline (for discussion of SOL device, see Cromdal, Danby, Emmison, Osvaldsson, \& Cobb-Moore, forthcoming). We show how membership categories referring to life span and family categories are "inference rich" (Sacks, 1972) in that a great deal can be understood through drawing on commonsense understandings located within the categories. 


\section{Some days where I'm the mum}

We focus in depth on one call where Hayley, a teenage caller, initially calls to talk about fighting with her sister and later reports that her mother is ill, and that she has extra responsibilities at home. Extract 3 starts just after the call begins, with Hayley describing how she has been fighting with her younger sister earlier that day, before adding that she fights often with her mother. Up until now, she is reporting on family relationships. The extract begins with the counsellor's formulation of the client's current circumstances.

\section{Extract 3 PC150508_1807}

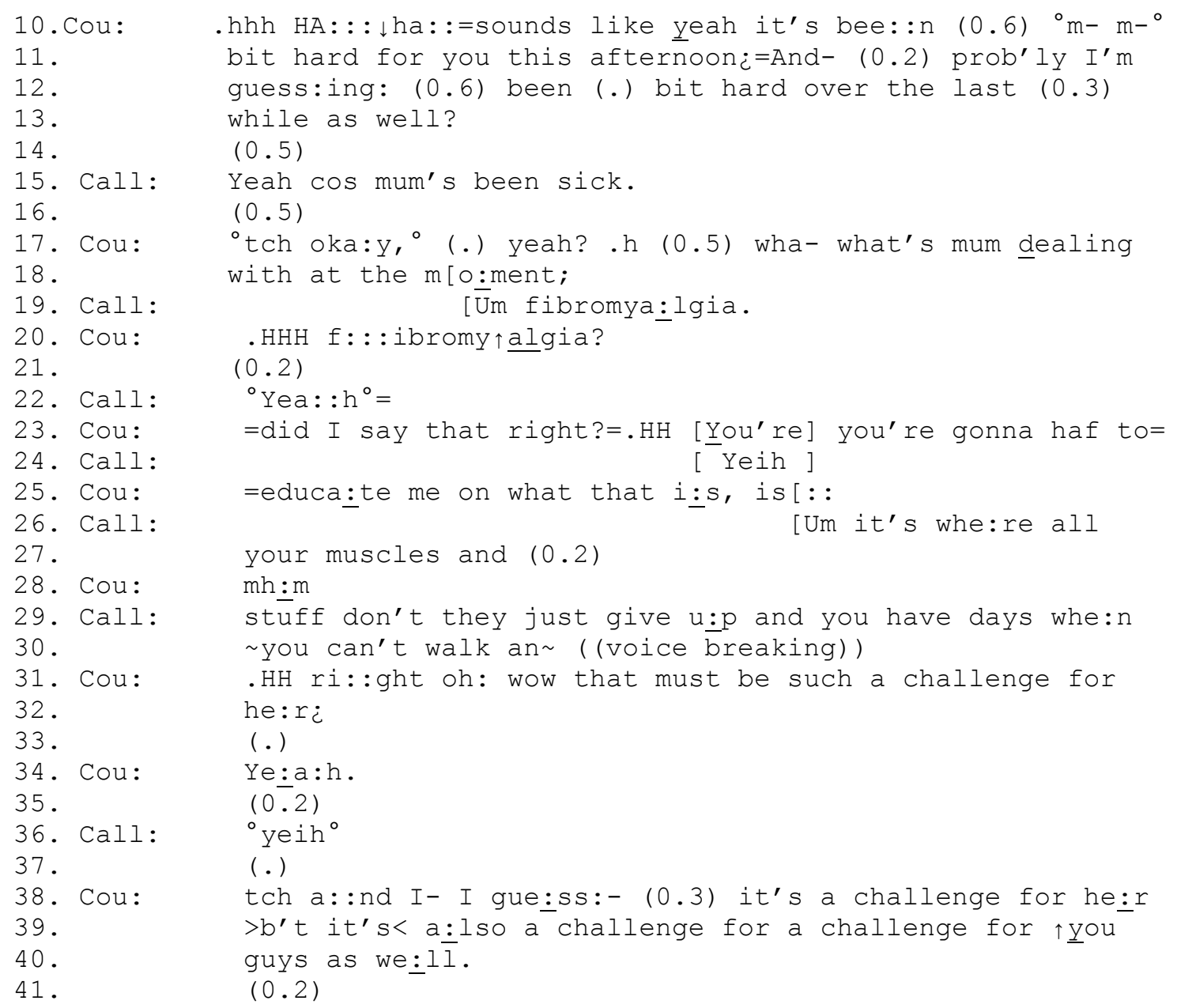


In this extract, Hayley presents her initial reason for her call to Kids Helpline, that of fighting with her sister. The counsellor initially responds to the specific incident that led to the call with an empathic formulation that it has been a "bit hard" for the caller this afternoon (line 11), and he "guesses" that it's been a hard for a while (lines 12-13). Hayley offers an agreement and expands by disclosing that her mother has been sick (line 15). The counsellor quietly receipts this, and follows with an upwardly rising "yeah?" and he follows up with a question specifically asking what her mum has been "dealing with at the moment" (lines 17-18). She names the illness, fibromyalgia (line 19). After repeating this, the counsellor asks her to "educate" him about it (lines 23 and 25), which works to put the client into an epistemic position of being more knowledgeable about the disease than the counsellor. This early work in the call by the counsellor is designed to encourage the caller to talk about her experiences and to minimize the inherent asymmetry found in professional-lay consultations (Heritage \& Sefi, 1992) and in adult-child interactions (Speier, 1973). This move by the counsellor also works to elicit the caller's perspective.

As the client describes her mother's condition, she stops when her voice starts breaking, and the counsellor responds in lines 31-32 with an a loud inbreath, drawn out receipt (ri::ght) and an assessment that it must be "such a challenge for her" (line 38). After a slight pause, the counsellor reinforces his perspective with an extended and downward falling "Ye:a:a:h" (line 34) to which the caller quietly agrees. The counsellor's slightly troubled delivery suggests attending to the delicacy of this matter (Silverman \& Peräkylä, 1990), and he returns the focus of the conversation from the mother back to the caller in the form of "you guys" (lines 3840), which provides the interactional space for the caller to talk more about her family situation, including how her father had to work two jobs (not shown in the transcript). The counsellor's turn invokes the family device, treating her account as a warrantable troubles telling. He now pursues Hayley's experiences of the family's challenges, and its impact on her (Extract 4). 


\section{Extract 4 PC150508_1807}

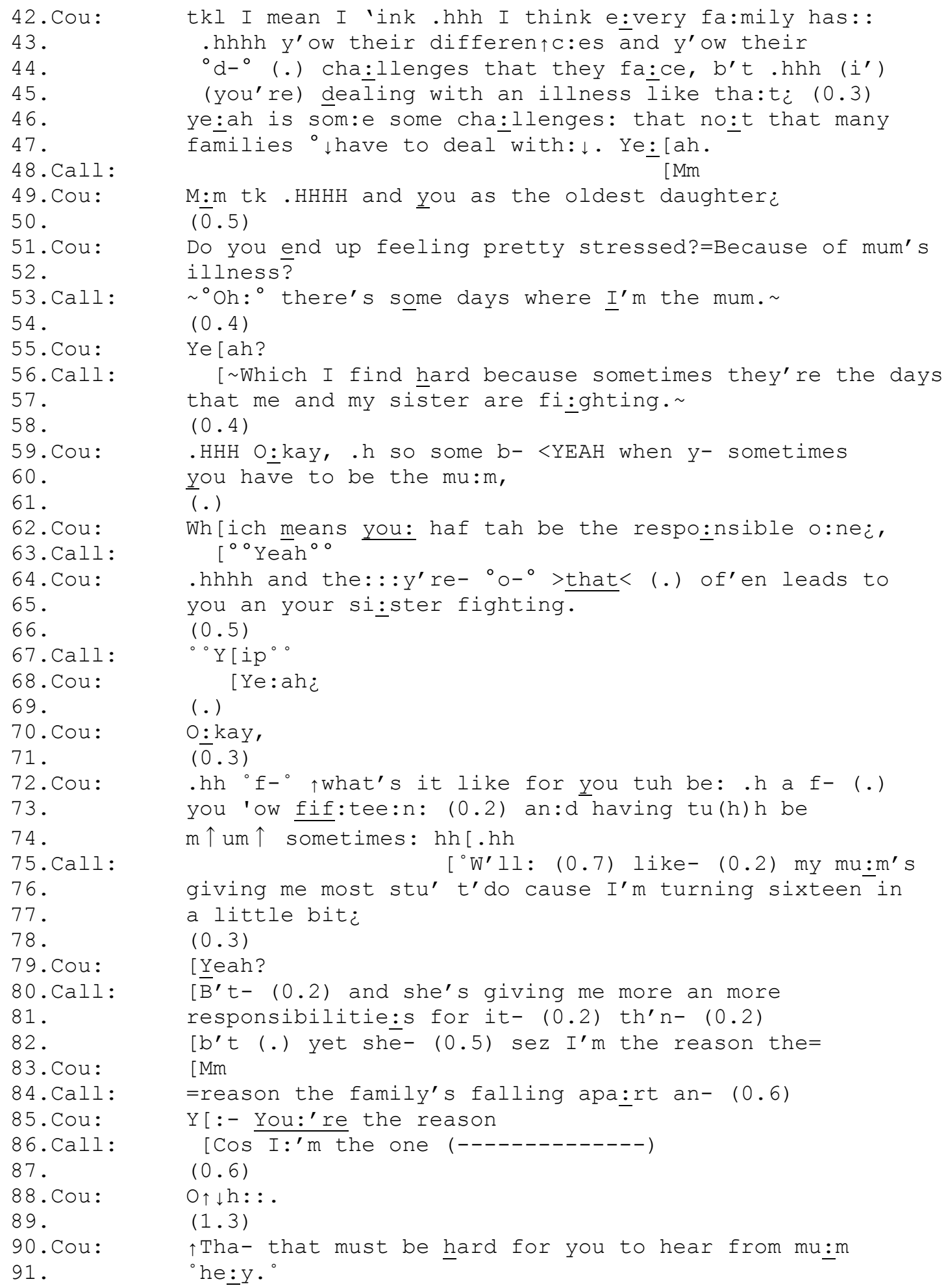

In lines 42-48, the counsellor invokes the 'family' device - first, by describing what 'every family' goes through, and the challenges they face, but then the challenges 
faced by the caller's family as extreme - beyond the norm. The counsellor picks up on the parts of the account to do with the "challenging stuff" that the caller has had to deal with in her family situation. In line 42 , the counsellor introduces the institution of family, shifting from the generic "every family" (line 42) to "your" family (lies 45-47) dealing with a particularly difficult situation. The counsellor's turn works to upgrade the magnitude of what the caller has identified, that the circumstances are beyond 'normal, and to elaborate on what it means for her family ("some challenges not too many families have to deal with", lines 46-47). By identifying the caller's situation as 'not normal,' the counsellor affiliates with the caller by assessing her situation as difficult. This summarising formulation gives the gist of what has been said so far, as well as ratifying her account (Antaki, 2008; Heritage \& Watson, 1979).

The counsellor extends on this version of the hardship faced by Hayley, not only as a member of a family with specific and extreme challenges, but as the 'older daughter' (line 49). This device brings commonsense understandings about the roles, rights and responsibilities attributed to different roles/categories within the device family. He has zoomed in on the caller's particular and personal challenges by virtue of her membership as the 'older daughter', invoking a distinct set of rights and responsibilities In this way, he validates and ratifies the caller's reported 'stress' as a consequence of having additional responsibilities due to her membership as 'oldest'. The categorization of 'older sister' invokes age, but it is relative to the ages of other children in the family - a relational category.

The counsellor continues by asking about "feeling pretty stressed", said quickly and latching to the reason, mum's illness (lines 51-52). In this way, the counsellor invokes the type of ranking and related distribution of family responsibilities, that the oldest daughter has greater responsibilities and can be expected to be more stressed than younger members of the family. The counsellor's categorization is crucial in ascribing a problem to the caller, and shows how the counselor draws on common sense cultural knowledge to preset his understanding of the client's telling. 
After the counsellor offered a formulation of the caller's emotional state and (justifiable) reason for this, via a categorization, the caller's 'oh-prefaced' response (Heritage, 1998) indicates her epistemic primacy over the relevance of the category ascription. Hayley then maps herself into a different category: 'some days I'm the mum'. With this self-categorisation, she upgrades the extent of her responsibilities as resulting in activities predicated to the 'mother' category. This draws on common-sense understandings, providing a snapshot of the situation, highlighting the scale of the problem she is having to cope with; as a teenager, her life situation has resulted in her having to act as the mother - 'there's some days where I'm the mum' (line 53). This works to upgrade the counsellor's categorization in terms of workload and domestic responsibilities. The role reversal serves to categorically upgrade the trouble description, still by drawing on the same kind of "what anyone knows" type of knowledge of the moral orders of families indexed by the counsellor's previous turn.

After a slight pause and the counsellor's encouraging "yeah?" to continue (line 55), Hayley provides an account of the consequence of having to be the mum, of assuming a position of authority and responsibility in the family, she gets into fights with her younger sister. The counsellor receipts Hayley's account with a formulation (59-60), elaborating on the trouble of being in both categories of mum and sister. He formulates an explanation of why the sisters are fighting, working from the common sense understanding of relationships between older and younger sisters. He provides the upshot of this formulation in line 62 by beginning to unpack the implied shared cultural knowledge in the identity claim - that being 'the mum' means being responsible, to which the caller agrees.

Following this agreement, the counsellor seeks her perspective about what it is like to be aged 15 and to be the mother (lines 72-74). The implication in the counsellor's description of being fifteen and having to be the mum (lines 72-73) suggests that the troubles she is experiencing might belong more rightfully within the category of 
being an adult rather than being associated with her chronological age. Here, the counsellor has introduced the stage-of-life device, with the categories of older sister and mum being mutually exclusive. The younger sister treats her as a sister, but Hayley is doing things via her membership as mum.

Using a quantifiable measure such as age can offer "a routine, reliable and objective way of describing someone, ... [and] can also function as a bottom-line argument, as the last resort for checking someone's 'objective' age-category" (Nikander, 2002). As Sacks (1995) points out, "the age class a person is in turns on the topic with respect to which they're being talked of" (Vol. 1, p. 754). In this way, we can see the counsellor suggesting to the client that there has been some breach of "some normative or common sense notions of age" (Nikander, 2002, p. 149).

In this extract, we saw how the counsellor made the family device relevant through introducing the category of the "oldest daughter", and displayed care and sympathy through his counsellor's affiliative stance and alignment that encouraged more talk

from the client. The counsellor's questions worked to demonstrate his awareness of the authenticity of client's own stated feelings. The delicate and sensitive categorisation worked because such categorisations are "inference rich" (Sacks, 1995, Vol. 1), displaying everyday understandings of social and cultural life.

\section{"i feel like the adult"}

In the previous extract, the counsellor initiated the family device through his introduction of the category of "oldest daughter". In the web session below (Extract 5 ), it is the client who initiates the stage-of-life (SOL) device by referring to herself: "I feel like the adult". Up until this point, the client had provided an account of how she was living in a family where her father had lost his job and was drinking a lot, that her mother had depression and that her elder sister was leaving home so that the client would be left alone to deal with the family situation. (The transcript is 
produced exactly as was shown the web page; see Endnote 1 at the end of this chapter for an explanation of how to understand the time stamps on the transcript.)

\section{Extract 5 WC103531}

(Counsellor) sounds like you're almost having to cope with this by yourself. Would am right in saying that?

16:13 09:36 01:43 yeh its pretty daunting. i feel like the adult in the situation trying

(Client) to work out what to do.. how to look after everything. pay for

$16: 1410: 1900: 43$ stuff. its just overwhelming. (Counsellor) that would be overwhelming. Overal, how do you feel you're
coping?

16:15 11:19 01:00 yeh not very well. hahe. i would lvoe to say i am brilliant and

(Client) coping just fine. but its not that case. i am in over my head dealing with it all

(Counsellor) sorry to hear that, sounds full on!

$16: 1512: 0200: 43$

$16: 17$ 13:28 01:26

(Counsellor) what are you wanting to do about the situation? How much longer do you think you can go on like this?

$16: 17$ 13:56 00:28 i dunno. i just dont know what to do. i wanna move out, but its kinda a race between me and my sister who goes first gets to (Client) go kinda thing. because whoever loses has to look after mum. and my sister already has plans to move so i lost. i just dont know.. im stuck

(Counsellor) that makes it difficult when you're wanting to look after your mum. Sounds like you really care for her

16:19 15:04 01:08

16:20 16:07 01:03

Extract 5 begins almost 10 minutes into the web chat session. At 09:36 (see the middle column that indicates the length of time that the web chat has been going; see Endnote 1), the counsellor provides an upshot of the family situation that the client has described. He brings the focus back to her and how she is having to cope with her family situation by herself. The client agrees, adding that it is "daunting", and introduces the stage of life (SOL) device, saying "i feel like the adult" (10:19). She follows with a gloss of what this entails, and finishes with an assessment using an extreme case formulation (Pomerantz, 1986) of "just overwhelming" that the counsellor picks up on, repeating this formulation, which works to show acceptance of the client's account.

The counsellor now shifts into a counselling sequence where he asks a series of questions. The first question is used to assess the client's assessment of her current 
situation from her personal perspective: "how do you feel you're coping?" (11:19). The client's next posting displays the intensity of her feelings through the contrasting positions she proposes: " $\mathrm{i}$ would lvoe to say i am brilliant and coping just fine. but its not that case. i am in over my head" (12:02). The client's idiomatic expression of being in "over her head' is unchallengeable (Drew \& Holt, 1988), and provides the counsellor with straight forward evidence from the client that she is not coping well at all, delivered as an upshot, or punchline (Sacks, 1995, Vol. 2, p. 48 ), as evidenced by the counsellor's next short post, proffering an empathic stance (13:28).

The client's previous turn now provides sufficient warrant for the counsellor to shift to a future-oriented action, "what are you wanting to do about the situation? How much longer do you think you can go on like this?" (13:56). The client's reply takes over a minute to post. She describes how she has lost the race with her sister (to move out of home) and that she will have to look after her mum as a consequence. Interspersed within this description, she provides a sequence of talk begins with " $\mathrm{i}$ dunno" to 'I just don't know" to "I just don't know..im stuck". This is categoryresonant with "being in over one's head." The final "im stuck" sums up the situation for the client and provides the jumping off point for the counsellor. The counsellor selects, from all this talk of wanting to move out, a formulation that recognizes that it is a difficult situation and it "sounds like" the client "really cares for her mum" (16.07).

Extract 6 continues 9 minutes after Extract 5, and both counsellor and client continue their discussion related to stage-of-life categories.

\section{Extract 6 WC103531}

I'm sorry to hear that you feel that way. A concern is how this is

(Counsellor) affecting your life and your future. How do you feel this is 16:29 25:30 01:27 affecting you?

(Client) um well i feel like i am like thirty. old before my time. i feel so run down. and just on the verge of my own personal breakdown. ya know. and $\mathrm{i}$ just want it to be someone elses 
problem and run away.. i also get scared that i will end up like her, bitter and resentful to everyone.

(Counsellor) it's understandable to feel that way considering what how you've been supporting her.

16:32 28:10 00:55

(Counsellor) It sounds like you're wanting more your life. What would you like to be doing?

$16: 32$ 28:44 00:34 i dunno being 18, clubbing, having friends, achieving stuff.

(Client) going places becoming famous. hahe. just normal stuff minus becoming famous.. hahe. tho that would be nice.

16:33 29:31 00:47 that's normal and what most people want. To enjoy life. Do you feel that you could take a backward step with things at home,

(Counsellor) still help out a bit but then also do the things you want to be?

Because when people aren't happy and helping themselves

16:36 32:40 03:09 then they aren't usually in a position to best help others. Do you know what I mean that?

The counsellor begins a series of questions seeking the client's perspective about her life situation. At 25:30 minutes into the web chat, the counsellor asks about she feels the family situation at home is affecting her. The client begins with a thinking token before going on to say that she feels 30 years old, and old before her time (27:15). Following empathic receipt from the counsellor and a formulation that "it sounds like" she is wanting more for her life, he continues his pursuit of her own perspective on her life, and asks a forward-projecting question about what she would "like to be doing" (28:44). The client's next post presents herself as being 18 (almost half the age she previously indicated she felt), and she produces a list of activities associated with commonsense norms of what teenagers like to do (clubbing, going places and so on). She finishes with what she'd like to do is "just normal stuff", meaning the sorts of normal stuff that teenage girls like to do (29:31).

In the client's presentation of herself, she established chronological age as a way of indicating a mismatch between what she is currently doing and what she would like to be doing as a teenager. Making chronological and lifespan categories relevant is one way to "describe and account for our own and others' actions" (Nikander, 2009, p. 864). As Atkinson (1980) points out, in '"growing up' ...one moves 'from' childhood 'into' adolescence and 'then into' adulthood" (p. 33). Growing up is part of the lifespan, but growing old before your time is not. She juxtaposes the mismatch of her "natural lifetime schema" (Atkinson, 1980) of what it is like for her now, using 
the age device of being almost double her current age, with the normative teenage experiences she would like to be doing. In this way, she makes immediately recognizable some features of normative and non-normative orders of the life span (Cromdal et al., forthcoming).

The counsellor picks up the client's account of what she would like to be doing, "that's normal" (32:40), which works to confirm and validate the client's perspective as not only her individual perspective but one that "most people" would want. Built into the counsellor's response is an acceptance and validation of the client's perspective that being a teenager has a normative distribution of rights and activities, such as clubbing. His post recognises and accepts the cultural knowledge embedded within the category of being a teenager. Once both counsellor and client agree on the shared category of being a teenager and associated normative activities, the counsellor works to explore ways that the client could manage the situation at home.

\section{Discussion}

In this chapter, we have shown extracts from a phone call and from a web chat session. In each, we presented an analysis of how clients reported their experiences of being in situations where they felt that, even though they were teenagers, they were acting as adults and having to take on adult-like roles of caring for parents and other family members. The focus on membership categories of family and stage-oflife highlight the normative assumptions that underpin everyday commonsense assumptions, made relevant by clients and counsellors as a way of talking about and making sense of the client's experiences.

We saw how the family and stage of life devices were made relevant as a way to describe the situation and to confirm and validate young people's accounts of their emotional states. Invoking categorization, counsellors oriented young people's circumstances to confirm, commend, validate or seek more information by probing and asking questions, and to produce formulations that displayed affiliation with the 
caller's stance, orienting to the caller as someone with feelings who is responding to an abnormal situation. The clients drew on family and stage of life (SOL) devices to build cases that displayed the extent of the problems they were facing at home, and the counsellors took up or introduced family and SOL devices to display an empathic hearing that displayed shared affiliation and validation of the clients' accounts.

We saw that counsellors and clients drew on the social structures and cultural norms as part of making sense of the young clients' experiences and situations. Clients invoked categorizations to describe what they were doing in the family context and how they felt about that. Counsellors invoked norms to validate the clients' experiences and also to address the client as an individual. In this way, commonsense family and stage-of-life categorizations are useful ways to understand normal development. Additionally, and shown through the counselling talk here, membership categorizations provide opportunities to show mismatches between cultural norms and the clients' own individual experiences and situations, and to use these understandings as a way of talking about the clients' own situations.

This chapter contributed to exploring ways in which analysis of membership categories and sequential conversation can jointly explicate how communication occurs on a children and young people's helpline. With our analytic focus on children and young people's accounts of their own experiences, we drew on how they made sense of the family and stage of life (SOL) categories. In other words, it was not the researchers' description but rather how the participants themselves organised their talk to draw on such category work.

\section{Clinical Relevance}

The chapter has focused on how young clients provide accounts of their activities and responsibilities within family life. Family issues are one of the main reasons that young callers contact Kids Helpline, and counselling sessions open up possibilities for discussing norms of family life, roles and relationships of family members, and family responsibilities. The analytic approach of membership 
categorization has shown that clients' accounts and experiences of disconnect between normative and actual responsibilities can be understood through commonsense category membership work. When there is mismatch within category membership (family and stage-of-life), these descriptions might inform clinicians of how clients discuss activities within 'dysfunctional' families, and provide clinical possibilities for how to explore these matters with clients.

Family situations are complex, and require sensitivity and understanding of the diversity of family contexts. Children and young people use counselling support across different modalities to report their troubles. Counsellors draw on a range of communication strategies to support the young clients to understand their particular contexts of family life. Counsellor strategies are designed to confirm, commend, validate and seek more information from the client by probing and asking, and clients are oriented to as someone with feelings and with the competence and resources to understand and find solutions to their troubles.

Clients and counsellors draw on commonsense knowledge of family relationships with their normative distribution of rights and responsibilities. This type of cultural knowledge is a built-in feature of membership categories, and shown here within the categorization work of both clients and counsellors as they make sense of the situation. Within this chapter, we showed that the counsellors went beyond a sense of shared understanding to proceed to expand the categorical relations that were invoked by clients and counsellors. The shared understanding develops into displays of affiliation that are oriented directly to the institutional philosophy of Kids Helpline: "we care, we listen."

The research findings of this chapter investigating how counsellors and young people interact on helplines address a broader research agenda. By taking these findings into account, this chapter argues against the use of prepared agendas or templates for counsellors to use when interacting with young people in helpline contexts. Building the clinician/client relationship requires a sensitive and skilled 
approach where counsellors actively listen to the clients' presentations of their concerns. This relationship is built moment by moment through the clinician-client interaction as it unfolds. The counsellor's work is to expand, with the client, shared understandings of family categories and relationships as they unfold. If the counsellor is constrained by service guidelines that require the counsellor to follow a template or stepped procedures on how to respond to the client, no template could ever fully consider the multiplicities of possibilities that the client might want to talk about, or the unfolding of the counselling session.

\section{Summary}

Analysing client-counsellor talk as it unfolds moment-by-moment shows how counsellors work within an institutional philosophy of empowering the young caller by recognising their competence and capacity to resolve their issues and to come up with resolutions to their problems. Analysis shows how both client and counsellor make family and age categories relevant, with openings for both commendation and acknowledgement (the counsellor's response to how the client has managed) and complaint (the client's account of missing out on the stage of life of being a teenager). The chapter contributes to understandings of service provision for children and young people, such as how counselors can communicate effectively with children and young people.

\section{Clinical practice highlights}

1. Family situations are complex, and require sensitivity and understanding of the diversity of family contexts, taking into account differing family, cultural and religious practices.

2. Counselling sessions can open up possibilities for discussing family life, roles and relationships of family members, and family responsibilities.

3. Invoking category membership (family and stage-of-life) descriptions might provide clinical possibilities for how to explore family matters with young clients.

4. Listening for mismatches between category membership can provide important clues for how clients discuss family matters and provide a strategy for clinicians for how to explore these concerns.

5. The clinician/client relationship is fragile and built moment by moment through the interaction as it unfolds. It would not be possible to achieve this quality interaction by following a prepared service guideline template on how to respond 
to the clients. An interactive approach is required where the clinician is able to expand, with the client, their shared understandings of family categories and relationships as they unfold.

\section{Recommended Reading (up to 5 )}

1. Atkinson, M. A. (1980). Some practical uses of "a natural lifetime". Human Studies, 3, 33-46.

2. Hester, S., \& Eglin, P. (1997). Membership categorization analysis: An introduction. In S. Hester \& P. Eglin (Eds.), Culture in action: Studies in membership categorization analysis (pp. 1-23). Washington, DC:

International Institute for Ethnomethodology and Conversation Analysis \& University Press of America.

\section{Endnotes}

1. The web chat session transcripts consist of three time slots: For example, in the $1^{\text {st }}$ line in extract 2 , the first slot [16:22] refers to the actual time of the interaction on a 24 hour clock. The second time slot refers to when the turn was posted [00:50], occurring 50 seconds into the interaction. The third time slot [00.41] identifies the lapse of time since the last posting, 41 seconds. We use the second slot to identify the line being discussed.

\section{Acknowledgements}

This project was supported by an Australian Research Council Discovery grant (Project ID: DP0773185) with ethical approval from Queensland University of Technology. We thank Kids Helpline and BoysTown, and the counsellors and clients who took part in the study.

\section{References}

Antaki, C. (2008). Formulations in psychotherapy. In A. Peräkylä, C. Antaki, S. Vehviläinen \& I. Leudar (Eds.), Conversation Analysis and psychotherapy (pp. 26-42). Cambridge: Cambridge University Press.

Antaki, C. (2008). Formulations in psychotherapy. In A. Peräkylä, C. Antaki, S. Vehviläinen \& I. Leudar (Eds.), Conversation Analysis and psychotherapy (pp. 26-42). Cambridge: Cambridge University Press.

Atkinson, M. A. (1980). Some practical uses of "a natural lifetime". Human Studies, 3, 33-46.

BoysTown. (2013). Giving Voice: BoysTown Annual Report 2013. Brisbane: BoysTown. 
Butler, C. W., Potter, J., Danby, S., Emmison, M., \& Hepburn, A. (2010). Advice Implicative Interrogatives: Building 'client centred' support in a children's helpline. Social Psychology Quarterly, 73(3), 265-287.

Castro, D. M., Jones, R. A., \& Mirsalimi, H. (2004). Parentification and the imposter phenomenon: An empirical investigation. The American Journal of Family Therapy, 32, 205-216.

Cromdal, J., Danby, S., Emmison, M., Osvaldsson, K., \& Cobb-Moore, C. (forthcoming). "An I said to her, I jis' wanna be a teenager": Stage of life categories on a children and young people's helpline.

Danby, S., Baker, C., \& Emmison, M. (2005). Four observations on opening calls to Kids Help Line. In C. D. Baker, M. Emmison \& A. Firth (Eds.), Calling for help: Language and social interaction in telephone helplines (pp. 133-151). Amsterdam/Philadelphia John Benjamins

Danby, S., Butler, C. W., \& Emmison, M. (2009). When 'listeners can't talk': Comparing active listening in opening sequences of telephone and online counselling Australian Journal of Communication, 36(3), 91-113.

DiCaccavo, A. (2006). Working with parentification: Implications for clients and counselling psychologists. Psychology and Psychotherapy: Theory, Research and Practice, 79, 469-478.

Drew, P., \& Holt, E. (1988). Complainable matters: The use of idiomatic expressions in making complaints. Social Problems, 35, 398-417.

Earley, L., \& Cushway, D. (2002). The parentified child. Clinical Child Psychology and Psychiatry, 7(2), 1359-1045.

Emmison, M., Butler, C., \& Danby, S. (2011). Script proposals: A device for empowering clients in counselling. Discourse Studies, 13(1), 3-26.

Emmison, M., \& Danby, S. (2007). Troubles announcements and reasons for calling: Initial actions in opening sequences in calls to a national children's helpline. Research on Language \& Social Interaction, 40(1), 63-87.

Garfinkel, H. (1991). Respecification: Evidence for locally produced, naturally accountable phenomena of order*, logic, reason, meaning, method, etc. in and as of the essential haecceity of immortal ordinary society, (I) - an announcement oof studies. In G. Button (Ed.), Ethnomethodology and the human sciences (pp. 10-19). Cambridge: Cambridge University Press.

Harris, J., Danby, S., Butler, C., \& Emmison, M. (2012). Extending client-centered Support: Counselors' proposals to shift from email to telephone counseling. Text and Talk, 32(1), 21-37.

Heritage, J. (1998). Oh-prefaced responses to inquiry. Language in Society, 27, 291334.

Heritage, J., \& Sefi, S. (1992). Dilemmas of advice: aspects of the delivery and reception of advice in interactions between health visitors and first-time mothers. In P. Drew \& J. Heritage (Eds.), Talk at Work: Interaction in Institutional Settings (pp. 359-417). Cambridge: Cambridge University Press.

Heritage, J., \& Watson, D. (1979). Formulations as conversational objects. In G. Psathas (Ed.), Everyday language: Studies in ethnomethodology (pp. 123-161). New York: Irvington Publishers. 
Hester, S., \& Eglin, P. (1997). Membership categorization analysis: An introduction. In S. Hester \& P. Eglin (Eds.), Culture in action: Studies in membership categorization analysis (pp. 1-23). Washington, DC: International Institute for Ethnomethodology and Conversation Analysis \& University Press of America.

Hooper, L. M. (2008). Defining and understanding parentification" Implications for all counsellors. The Alabama Counselling Association Journal, 34(1), 34-43.

Jankowski, P. J., Hooper, L. M., Sandage, S., \& Hannah, N. J. (2013). Parentification and mental health systems: mediator effects of perceived unfairness and differentiation of self. Journal of Family Therapy, 35, 43-65. doi: 10.1111/j.1467-6427.2011.00574.x

Leon, K., \& Rudy, D. (2005). Family processes and children's representations of parentification. Journal of Emotional Abuse, 5(2-3), 111-142.

McMahon, T. J., \& Luthar, S. S. (2007). Defining characteristics and potential consequences of caretaking burden among children living in urban poverty. American Journal of Orthopsychiatry, 77(2), 267-281.

Nikander, P. (2002). Age in action: Membership work and stages of life categories in talk. Helsinki: The Finish Academy of Science and Letters.

Nikander, P. (2009). Doing change and continuity : age identity and the micro-macro divide. Ageing \& Society, 29, 863-881.

Pomerantz, A. (1986). Extreme case formulations: A way of legitimizing claims. Human Studies, 9, 219-229.

Sacks, H. (1972). An initial investigation of the usability of conversational data for doing sociology. In D. Sudnow (Ed.), Studies in social interaction (pp. 31-74). New York: The Free Press.

Sacks, H. (1995). Lectures on conversation (G. Jefferson, Trans. Vol. I and II). Oxford, UK: Blackwell.

Silverman, D., \& Peräkylä, A. (1990). AIDS counselling: The interactional organisation of talk about "delicate" issues. Sociology of Health and Illness, 12(3), 293-318.

Speier, M. (1973). How to observe face-to-face communication: A sociological introduction. Pacific Palisades, CA: Goodyear Publishing Company.

Stiffler, D., Barada, B., Hosei, B., \& Haase, J. (2008). When Mom has breast cancer: Adolescent daughters' experiences of being parented. Oncology Nursing Forum, 35(6), 933-940.

Van Parys, H., \& Rober, P. (2013). Trying to comfort the parent: A qualitative study of children dealing with parental depression. Journal of Marital and Family Therapy, 39(3), 330-345. 